San Jose State University

SJSU ScholarWorks

Master's Theses

Master's Theses and Graduate Research

1999

\title{
Internal and external rotation strength values of female swimmers and water polo players
}

Christopher Ferry

San Jose State University

Follow this and additional works at: https://scholarworks.sjsu.edu/etd_theses

\section{Recommended Citation}

Ferry, Christopher, "Internal and external rotation strength values of female swimmers and water polo players" (1999). Master's Theses. 1808.

DOI: https://doi.org/10.31979/etd.f6vx-ce5d

https://scholarworks.sjsu.edu/etd_theses/1808

This Thesis is brought to you for free and open access by the Master's Theses and Graduate Research at SJSU ScholarWorks. It has been accepted for inclusion in Master's Theses by an authorized administrator of SJSU ScholarWorks. For more information, please contact scholarworks@sjsu.edu. 


\section{INFORMATION TO USERS}

This manuscript has been reproduced from the microfilm master. UMI films the text directly from the original or copy submitted. Thus, some thesis and dissertation copies are in typewriter face, while others may be from any type of computer printer.

The quality of this reproduction is dependent upon the quality of the copy submitted. Broken or indistinct print, colored or poor quality illustrations and photographs, print bleedthrough, substandard margins, and improper alignment can adversely affect reproduction.

In the unlikely event that the author did not send UMI a complete manuscript and there are missing pages, these will be noted. Also, if unauthorized copyright material had to be removed, a note will indicate the deletion.

Oversize materials (e.g., maps, drawings, charts) are reproduced by sectioning the original, beginning at the upper left-hand corner and continuing from left to right in equal sections with small overlaps. Each original is also photographed in one exposure and is included in reduced form at the back of the book.

Photographs included in the original manuscript have been reproduced xerographically in this copy. Higher quality 6" $\times 9$ " black and white photographic prints are available for any photographs or illustrations appearing in this copy for an additional charge. Contact UMI directly to order.

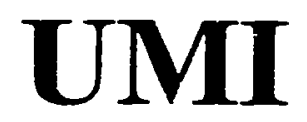

A Bell \& Howell Information Company 300 North Zeeb Road, Ann Arbor MI 48106-1346 USA 



\title{
INTERNAL AND EXTERNAL ROTATION STRENGTH VALUES \\ OF FEMALE \\ SWIMMERS AND WATER POLO PLAYERS
}

\author{
A Project \\ Presented to \\ The Faculty of the Department of Human Performance \\ San Jose State University \\ In Partial Fulfillment \\ of the Requirements for the Degree \\ Master of Arts
}

by

Christopher Ferry

May, 1999 
OMI Number: 1394520

UMII Microform 1394520

Copyright 1999, by UMI Company. All rights reserved.

This microform edition is protected against unauthorized copying under Title 17, United States Code.

\section{UMI}

300 North Zeeb Road

Ann Arbor, MI 48103 
(ㄷ) 1999

Christopher Ferry

ALL RIGHTS RESERVED 
APPROVED FOR THE DEPARTMENT OF HUMAN PERFORMANCE

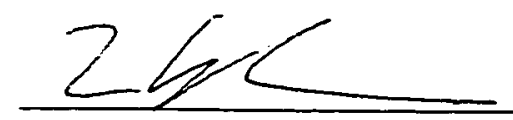

Leamor Kahanov

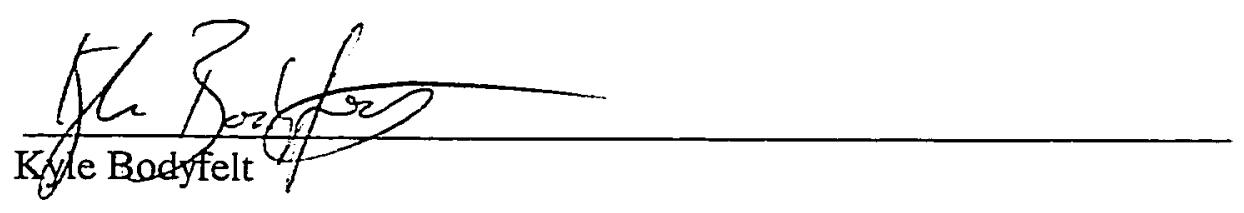

Uemutacua

Deva Reeder

APPROVED BY THE UNIVERSITY

William Risk 


\section{ABSTRACT \\ INTERNAL AND EXTERNAL ROTATION STRENGTH VALUES OF FEMALE SWIMMERS AND WATER POLO PLAYERS \\ by Christopher Ferry}

Rehabilitation programs for swimmers and water polo players with shoulder injuries have historically been identical, yet there exists inherent biomechanical and training differences between the two sports. The purpose of this study was to determine if a shoulder strength difference exists between swimmers and water polo players. Twenty-five subjects (10 swimmers and 15 water polo players) performed an isokinetic test on the Biodex, System 2. The subjects were tested in two different arm positions (45 and 90 degrees of shoulder abduction in the scapular plane) and three different speeds $(60,240$, and 450 degrees/second). Mann-Whitney non-parametric tests were calculated on the tests in 90 degrees of shoulder abduction at a speed of 450 degrees/second speeds for peak torque and total work. No statistically significant differences between the two sports were found, however, the swimmers showed a higher mean on 22 of the 24 tests performed. Practically, 3 of the 4 tests indicated visible differences suggesting that individual rehabilitation programs for shoulder injuries need to be designed separately and specifically for swimmers and water polo players. 


\section{ACKNOWLEDGMENTS}

I very much like to send thanks to the following people for without whose help, this study would not have possible. First, I would like to thank my committee, Leamor, Kyle and Dava, for all of their help, guidance, and persistence to make sure this study was done to the best of its ability. I would like to send a special thanks to the coaches and athletes of the Women's Swimming and Women's Water Polo teams at Stanford University. Without them, I would have nothing. Finally, thank you to the following people who played integral roles in helping me complete this project: Dr. Bethany Shifflett, Shane Meschke, T.J. Recinella, the athletic training staff at Stanford University and last but not least, Lorianne Warmbold. Thanks again. 
TABLE OF CONTENTS

Table of Figures.......................................... viii

Table of Tables.............................................

Project: Article Submission..............................

Cover Page .........................................

Submission Letter..................................

Release From ..................................... 3

Release Form for Photographs...................... 4

Abstract........................................... 5

Introduction.......................................

Methods ............................................

Results.......................................... 9

Conclusions .......................................

References........................................ 16

Expanded Support Material................................ 18

Introduction ...............................................

Purpose of this Project................................ 21

Significance of this Study ............................

Delimitations.....................................

Limitations.......................................

Assumptions.....................................

Statement of the Hypothesis......................... 22 
Definition of Terms...............................

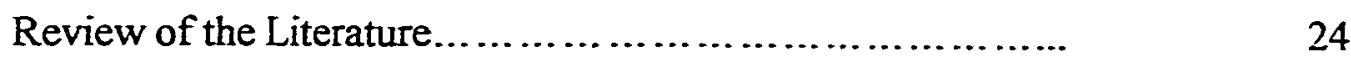

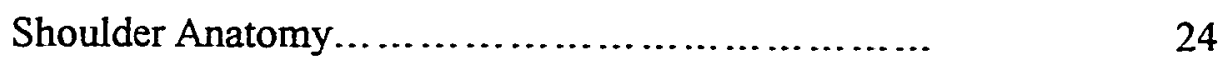

Overview of Overhead Athletes...................... 27

Overview of Swimmers and Water Polo Players......... 30

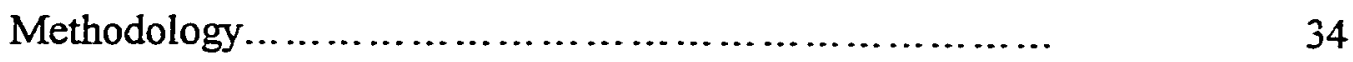

Subjects and Sampling .............................

Testing Apparatus.................................

Testing Protocol....................................

Statistical Analysis................................

Submission Statement...............................

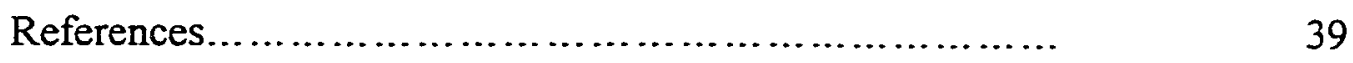

Appendix A - Informed Consent Form....................... 43

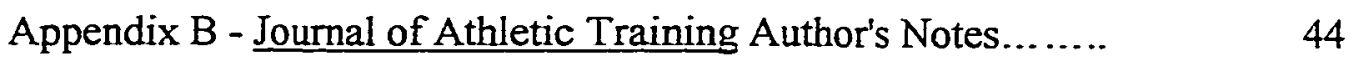




\section{TABLE OF FIGURES}

Figure A. Shoulder complex anatomy anterior............................ 24

Figure B. Shoulder complex anatomy posterior .......................... 25

Figure C. Biodex, System 2 setup for 90 degrees of shoulder abduction..... 35

Figure D. Biodex, System 2 setup for 45 degrees of shoulder abduction..... 35

Figure E. Elbow stabilization with velcro straps....................... 36

Figure F. External rotation in the scapular plane (overhead view)........... 37 


\section{TABLE OF TABLES}

Table 1. Peak Torque Means and Standard Deviations for

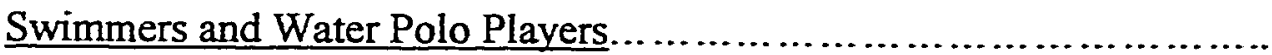

Table 2. Total Work Means and Standard Deviations for

Swimmers and Water Polo Players....................................

Table 3. Demographic Information of Swimmers

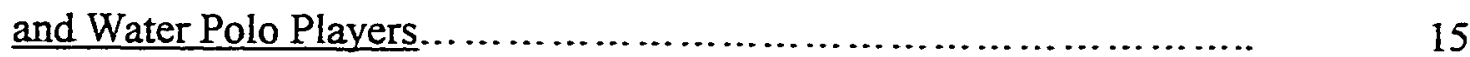

Table 4. Mean Rotational Peak Torque Value and Standard Deviations

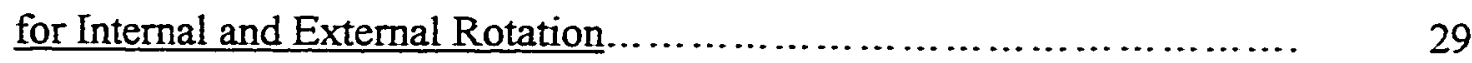

Table 5. Mean Rotational Total Work Values for Internal and

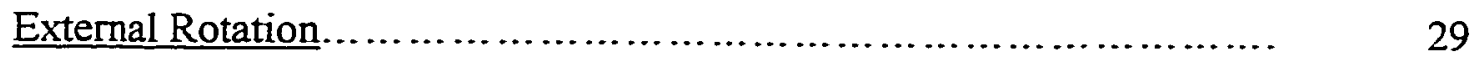

Table 6. Mean Values and Standard Deviations of Adduction and

Abduction in External and Internal Rotation Ratios

in the Control and Polo Groups......................................... 
INTERNAL AND EXTERNAL ROTATION STRENGTH VALUES

OF FEMALE

SWIMMERS AND WATER POLO PLAYERS

\author{
By \\ Christopher Ferry \\ San Jose State University \\ Leamor Kahanov \\ San Jose State University \\ Program Director-Graduate Athletic Training \\ One Washington Square \\ San Jose, CA 95192-0054 \\ 408-924-3040 \\ leamor@email.sjsu.edu \\ Kyle Bodyfelt \\ San Jose State University \\ Dava Reeder \\ Stanford University
}


This manuscript contains original unpublished material that has been submitted solely to the Journal of Athletic Training and is not under simultaneous review by any other publication and will not be submitted elsewhere until a decision has been made concerning its suitability for publication by the Journal of Athletic Training. In consideration of the NATA's taking action in reviewing and editing my submission, I the undersigned author hereby transfer, assign, or otherwise convey all copyright ownership to the NATA, in the event that such work is published by the NATA. Further, I verify that I have contributed substantially to this manuscript as outlined in item \#3 of the current Author's Guide.

Christopher Ferry Leamor Kahanov 


\section{RELEASE FORM}

Permission to release borrowed material:

Date

To:

I am writing to request permission to reprint the following material from your publication:

Author(s):

Title:

Date of Publication:

Page(s):

Figure(s);

This material will be included in submission of the following manuscript to the Journal of Athletic Training:

Author(s):

Title:

Full credit will be given to the author(s) and the publisher. If you have a preference as to the wording of the credit line, please provide that information at the bottom of this form.

Two copies of this release are provided. Please retain one and return the other to me. Thank You.

Permission is granted for use of the material stipulated.

Signature:

Date:

Title: 


\section{RELEASE OF PHOTOGRAPHS}

Date

I, hereby give my permission for photographs of me be printed in this manuscript entitled

" by

authors in the

Journal of Athletic Training. I realize my name will remain strictly confidential.

Signature of Subject

Signature of Primary Author 


\begin{abstract}
INTERNAL AND EXTERNAL ROTATTON STRENGTH VALUES OF

INTERCOLLEGIATE FEMALE SWIMMERS AND WATER POLO PLAYERS
\end{abstract}

Objective - The objective of this study was to determine shoulder strength differences between female swimmers' and water polo players' internal and external rotation peak torque and total work values.

Design and Setting - Subjects performed an isokinetic test on the Biodex, System 2. The subjects were tested in two different arm positions ( 45 and 90 degrees of shoulder abduction) and three different speeds $(60,240,450$ degrees/second).

Subjects - Ten female swimmers and 15 female water polo players from a Division I university.

Measurements - Four Mann-Whitney non-parametric tests were calculated on the test scores in internal and external rotation in 90 degrees of shoulder abduction at 450 degrees/second examining peak torque and total work. Demographic data was also summarized using means and standard deviations.

Results - No statistical significance was present between these populations. A moderate level of practical significance was present. A comparison of the means showed that the swimmers had an increased strength value on 22 of the 24 tests.

Conclusions - Swimmers were identified as stronger than the water polo players. Practically, 3 of the 4 statistical tests indicated visible differences suggesting individual rehabilitation programs for shoulder injuries need to be designed separately and specifically for swimmers and water polo players

Key Terms - Shoulder strength, internal rotation, external rotation, isokinetic testing device, scapular plane 
Shoulder injuries have been cited as one of the major reasons for time loss in competitive swimmers. ${ }^{1}$ Elite level swimmers and water polo players endure similar training schedules, relying primarily on free-style swimming for conditioning, creating repetitive overhead shoulder movements that can frequently lead to overuse injuries and soft tissue micro-trauma. ${ }^{1}$ Two main orthopedic problems in these populations appear to be a combination of impingement and instability, lending to labral changes and increased glenohumeral laxity. ${ }^{2-5}$ Historically, shoulder rehabilitation programs have been similar for water polo and swimming, however, inherent differences between the two sports may indicate the need for modified shoulder rehabilitation protocols. For instance, compared to swimming stresses alone in swimmers, water polo stresses are a combination of swimming and throwing activities. ${ }^{2}$

Standard strength values have been used as baselines for injury goals during the rehabilitation of joints such as the knee and ankle. ${ }^{10,11,12}$ Standard internal and external rotation strength values could be used in the rehabilitation programs for swimmers and water polo players, however, preliminary studies of the rotator cuff between these sports indicate differences in strength. ${ }^{1,6,8,9}$ Male water polo players have been found to have significantly stronger rotator cuff strength and a muscle imbalance between internal and external rotation ${ }^{9}$ compared to swimmers who have no statistical side-to-side strength differences. ${ }^{1}$ The limited amount of research regarding internal and external rotation strength levels in water polo players and swimmers, questions current rehabilitation and prevention practices for these athletes. Studies have suggested a difference between internal and external rotation of water sports and other overhead activities ${ }^{5,9,12}$; though 
no studies have examined female swimmers and water polo players to determine internal and external rotation strength differences in these two sports.

The purpose of this study is to examine the internal and external rotation peak torque and total work of elite female swimmers and water polo players to determine if strength differences exist between these two sports. This data can potentially be used as baselines/goals for female swimmers and water polo players during the rehabilitation of shoulder injuries.

\section{METHODS}

\section{SUBJECTS}

Fifteen female collegiate varsity swimmers and ten female collegiate varsity water polo players $(\mathrm{n}=25)$ from a Division IA university were chosen to serve as subjects. All subjects signed a consent form prior to testing that was approved by the human subjects committee at San Jose State University and Stanford University. Each subject had their dominant shoulder tested. Hand dominance was determined in the water polo players by the arm with which the individual throws with and in the swimmers by the hand with which the individual writes. Subjects were excluded if they suffered from an existing shoulder injury or have had a significant shoulder injury requiring extensive rehabilitation or surgery in the past year (12 months).

\section{PROTOCOL}

Each subject was tested for peak torque and total work in internal rotation and external rotation on the Biodex, System 2 isokinetic testing device (Medical Systems Inc., Shirley, New York). The Biodex, System 2 was calibrated regularly during testing 
according to the set standards in the Biodex, System 2 handbook. The subjects were tested at 60 degrees per second, 240 degrees per second, and 450 degrees per second in the scapular plane ${ }^{7}$ and at 45 and 90 degrees of shoulder abduction. Subjects were tested twice to determine reliability with a minimum of one day between testing.

All subjects were tested in loose-fitting clothes (athletic shorts and T-shirts) to eliminate shoulder restrictions during testing. The subjects were then positioned into the Biodex after an initial warm-up was completed.

Each subject was tested in the seated position while secured to the chair on the Biodex, System 2. The subjects were secured to the chair with straps across the waist and across the tested shoulder to ensure no accessory trunk movement. The tested arm was placed into the dynamometer with the shoulder internal and external rotation attachment on the Biodex, System 2 according to the testing protocol. The elbow was stabilized with velcro straps and flexed to 90 degrees. The uninvolved arm remained in the neutral position at the subject's side during testing.

Verbal instructions explaining the testing procedure were given. Each subject was given a countdown from 3 before the start of each test. Verbal cues were also given to the subject to encourage maximum effort. Each subject performed concentric contractions of internal rotation and external rotation at each test speed and degree of shoulder abduction. Internal rotation was measured from the arm in the plane of the scapula until it approximates with the trunk and external rotation was measured from the arm in the plane of the scapula until it reaches its anatomical limit. The subjects performed 5 repetitions at 60 degrees per second, 15 repetitions at 240 degrees per 
second and 15 repetitions at 450 degrees per second. Both of these sets were tested at 45 and 90 degrees of shoulder abduction with a one-minute rest period between all tests.

All data was collected and stored in the Biodex, System 2 computer.

Confidentiality was maintained indicating only the subjects' sport and gender on the data sheets. The Biodex, System 2 computer was used to print the record and each data sheet. Each data sheet was then identified solely as a swimmer or water polo player.

Descriptive statistics were used to determine the mean and standard deviation of the peak torque and total work values produced by each muscle group (internal/external rotators) of the dominant shoulder at each speed and degree of shoulder abduction. Demographic data (height, weight, and age) was also reported. Four Mann-Whitney tests were performed (internal/external rotators) to compare the peak torque and total work values of the two sports' athletes.

\section{RESULTS}

Both teams were similar with respect to height, weight, and age. The assumptions for the independent t-test (normality) were violated, therefore, four nonparametric Mann-Whitney tests were performed to differentiate the internal and external rotation peak torque and total work values between the swimmers and water polo players. An alpha level of 0.0125 was used ( $\alpha=0.05 / 4$ tests). Four isokinetic tests used were at 90 degrees of shoulder abduction with a speed of 450 degrees per second in internal and external rotation. The first two tests examined peak torque while the last two tests examined the total work performed. This test position was used because it provided the most functional arm position and speed that the athletes experience during regular 
activities. The results of the Mann-Whitney tests were compared to the $p$ value and were not found to be statistically significant. However, when the means of the tests were compared, the swimmers showed a higher mean score on 22 of the 24 tests performed (see Table 1 and 2). Reliability coefficients were calculated on the peak torque and total work values of internal and external rotation between the first and second tests. The internal rotation peak torque values had a reliability coefficient of 0.829 while the external rotation peak torque values had a reliability coefficient of 0.4244 . The internal rotation total work values had a reliability coefficient of 0.832 while the external rotation values had a reliability coefficient of 0.8724 . These values indicate that the data was stable across measures. The results indicate a moderate level of practical significance. These values of practical significance were 0.43 for the peak torque/internal rotation test, 0.07 for the peak torque external/rotation test, 0.54 for the total work/internal rotation test, and 0.62 for the total work/external rotation test. Power was calculated and determined to be very low $(<0.30)$ in this study.

\section{CONCLUSIONS}

Although the results were not found to be statistically significant, a moderate level of practical significance was present. The data indicates that the swimmers have higher mean peak torque and total work value for both internal and external rotation compared with the water polo players. This is the first study to compare swimming and water polo rotator cuff strength values. Previous studies have examined elite swimmers and water polo players and compared their subjects to a control group ${ }^{1,9}$, which does not allow for comparisons between sports or rehabilitation protocols for individual sports. 
The purpose of this study was to determine if a difference exists between swimming and water polo athlete rotator cuff strength. Results indicate a practical difference between both groups. Swimmers have a stronger rotator cuff suggesting that rehabilitation goals for strength should be higher than water polo players comparatively. Rehabilitation programs should look at the different function of the two sports to specifically target the needs of the swimmers and water polo players individually. The ideology that the "swimming athlete" should be rehabilitated in the same manner should be modified. In addition, shoulder strength of water polo players has the added functional component of throwing, which should also be incorporated into water polo shoulder rehabilitation programs.

Several variables may have had an influence on the variability of the external rotation/peak torque test including: the number of years that the subject has participated in their respective sport, the stroke and distances specific to the swimmers or the position played on the water polo team and the previous experience of the water polo player. Many water polo players have a strong swimming background. These uncontrolled variables may have effected the outcome of the study.

\section{RECOMMENDATIONS FOR FURTHER STUDY}

Several issues in this study may have influenced the outcome of the study and should be addressed in future research. Even though the subject was secured to the Biodex, System 2, there was no exceptional way to immobilize the elbow during testing, particularly at 90 degrees of shoulder abduction. Subjects did not follow the same warmup protocols. Some subjects were tested following a practice session and some 
performed the warm-up on the UBE. Also, a larger sample size may influence the end results.

Finally, more studies need to be conducted, including EMG analysis of the shoulder, to assess trunk stability between swimming and water polo athletes to create more comprehensive and accurate rehabilitation protocols. 
Table 1. Peak Torque Means and Standard Deviations for Swimmers and Water Polo Players

\begin{tabular}{|c|c|c|c|c|}
\hline & \multicolumn{2}{|c|}{ Swimmers $(n=10)$} & \multicolumn{2}{|c|}{ Water Polo $(n=15)$} \\
\hline $\begin{array}{c}\text { Test } \\
\text { Peak Torque }\end{array}$ & $\begin{array}{c}\text { Mean } \\
\text { (ft./lbs.) }\end{array}$ & $\begin{array}{l}\text { Standard } \\
\text { Deviation }\end{array}$ & $\begin{array}{l}\text { Mean } \\
\text { (ft./lbs.) }\end{array}$ & $\begin{array}{c}\text { Standard } \\
\text { Deviation }\end{array}$ \\
\hline $45^{\circ}$ Abduction $\mathrm{IR} 60^{\circ} / \mathrm{sec}$ & 30.78 & 3.77 & 30.43 & 5.99 \\
\hline $45^{\circ}$ Abduction IR 240\%/sec & 31.95 & 4.84 & 29.90 & 5.05 \\
\hline $45^{\circ}$ Abduction $\mathbb{R} 450^{\circ} / \mathrm{sec}$ & 36.04 & 5.30 & 34.63 & 5.26 \\
\hline $45^{\circ}$ Abduction ER $60^{\circ} / \mathrm{sec}$ & 15.47 & 6.58 & 13.38 & 3.33 \\
\hline $45^{\circ}$ Abduction ER $240^{\circ} / \mathrm{sec}$ & 15.34 & 6.21 & 13.81 & 3.02 \\
\hline $45^{\circ}$ Abduction ER $450^{\circ} / \mathrm{sec}$ & 16.18 & 7.57 & 15.27 & 2.87 \\
\hline $90^{\circ}$ Abduction $\mathbb{I R} 60^{\circ} / \mathrm{sec}$ & 32.67 & 4.75 & 30.15 & 4.93 \\
\hline $90^{\circ}$ Abduction $\mathbb{R} 240^{\circ} / \mathrm{sec}$ & 32.91 & 4.83 & 30.76 & 5.41 \\
\hline $90^{\circ}$ Abduction IR $450^{\circ} / \mathrm{sec}$ & 38.18 & 5.51 & 35.50 & 6.89 \\
\hline $90^{\circ}$ Abduction ER $60^{\circ} / \mathrm{sec}$ & 12.61 & 3.59 & 13.06 & 3.25 \\
\hline $90^{\circ}$ Abduction ER $240^{\circ} / \mathrm{sec}$ & 12.43 & 4.37 & 11.44 & 3.65 \\
\hline $90^{\circ}$ Abduction ER $450^{\circ} / \mathrm{sec}$ & 14.43 & 3.74 & 14.13 & 3.89 \\
\hline
\end{tabular}


Table 2. Total Work Means and Standard Deviations for Swimmers and Water Polo Players

\begin{tabular}{|c|c|c|c|c|}
\hline & \multicolumn{2}{|c|}{ Swimmers $(n=10)$} & \multicolumn{2}{|c|}{ Water Polo $(n=15)$} \\
\hline $\begin{array}{c}\text { Test } \\
\text { Total Work } \\
\end{array}$ & $\begin{array}{c}\text { Mean } \\
\text { (ft./lbs.) }\end{array}$ & $\begin{array}{l}\text { Standard } \\
\text { Deviation }\end{array}$ & $\begin{array}{l}\text { Mean } \\
\text { (ft./lbs.) }\end{array}$ & $\begin{array}{l}\text { Standard } \\
\text { Deviation }\end{array}$ \\
\hline $45^{\circ}$ Abduction $\mathbb{R} 60^{\circ} / \mathrm{sec}$ & 202.48 & 54.61 & 184.52 & 45.38 \\
\hline $45^{\circ}$ Abduction IR $240 \% / \mathrm{sec}$ & 505.64 & 158.43 & 427.27 & 97.11 \\
\hline $45^{\circ}$ Abduction $\mathbb{R} 450^{\circ} / \mathrm{sec}$ & 450.41 & 150.16 & 376.18 & 81.03 \\
\hline $45^{\circ}$ Abduction ER $60^{\circ} / \mathrm{sec}$ & 89.22 & 62.31 & 68.81 & 19.23 \\
\hline $45^{\circ}$ Abduction ER $240^{\circ} / \mathrm{sec}$ & 126.86 & 43.57 & 112.62 & 35.04 \\
\hline $45^{\circ}$ Abduction ER $450^{\circ} / \mathrm{sec}$ & 149.76 & 125.21 & 105.17 & 28.72 \\
\hline $90^{\circ}$ Abduction IR $60^{\circ} / \mathrm{sec}$ & 209.15 & 45.71 & 192.96 & 31.65 \\
\hline $90^{\circ}$ Abduction IR $240^{\circ} / \mathrm{sec}$ & 523.96 & 176.02 & 474.56 & 99.03 \\
\hline $90^{\circ}$ Abduction IR $450^{\circ} / \mathrm{sec}$ & 476.82 & 153.83 & 411.04 & 91.88 \\
\hline $90^{\circ}$ Abduction ER $60^{\circ} / \mathrm{sec}$ & 75.43 & 36.73 & 87.17 & 107.89 \\
\hline $90^{\circ}$ Abduction ER $240 \% \mathrm{sec}$ & 130.72 & 98.17 & 102.46 & 55.80 \\
\hline $90^{\circ}$ Abduction ER $450 \% \mathrm{sec}$ & 127.95 & 81.24 & 90.24 & 39.76 \\
\hline
\end{tabular}


Table 3. Demographic Information of Swimmers and Water Polo Players

\begin{tabular}{lcccc} 
& \multicolumn{2}{c}{ Swimmers $(\mathrm{n}=10)$} & \multicolumn{2}{c}{ Water Polo $(\mathrm{n}=15)$} \\
\hline Meight $(\mathrm{cm})$ & Mean & $\begin{array}{c}\text { Standard } \\
\text { Deviation }\end{array}$ & Mean & $\begin{array}{c}\text { Standard } \\
\text { Deviation }\end{array}$ \\
Weight $(\mathrm{kg})$ & 176.28 & 7.21 & 176.07 & 6.12 \\
Age (years) & 331.32 & 30.23 & 345.49 & 35.07 \\
& 19.10 & 1.37 & 19.24 & 1.16 \\
\hline
\end{tabular}




\section{REEERENCES}

1. Magnusson SP, Constantini NW, McHugh MP, Gleim GW. Strength profiles and performance in masters' level swimmers. The American Journal of Sports Medicine. $1995 ; 23: 626-631$.

2. Dominguez RH. Water polo injuries. Clinics in Sports Medicine. 1986;5:169-183.

3. Wilk KE, Arrigo CA, Andrews JR. Current concepts: The stabilizing structures of the glenohumeral joint. Journal of Orthopaedic and Sports and Physical Therapy. 1997;26:364-379.

4. Hart DL, Carmichael SW. Biomechanics of the shoulder. Journal of Orthopaedic and Sports and Physical Therapy. 1985;6:229-234.

5. Copeland S. Throwing injuries of the shoulder. British Journal of Sports Medicine. 1993;27:221-227.

6. Chandler JT, Kibler WB, Stracener EC, Ziegler AK, Pace B. Shoulder strength, power, and endurance in college tennis players. The American Journal of Sports Medicine. 1992;20:455-458.

7. Hartsell HD, Forwell L. Postoperative eccentric and concentric isokinetic strength for the shoulder rotators in the scapular and neutral planes. Journal of Orthopaedic and Sports and Physical Therapy. 1997;25:19-24.

8. Brown LP, Niehues SL, Harrah A, Yavorsky P, Hirshman HP. Upper extremity range of motion and isokinetic strength of the internal and external rotators in major league baseball players. The American Journal of Sports Medicine. 1988;16:577-585.

9. McMaster WC, Long SC, Caiozzo VJ. Isokinetic torque imbalances in the rotator cuff of the elite water polo player. The American Journal of Sports Medicine. 1991;19:7275.

10. Vaz $\mathrm{MD}$, Kramer $\mathrm{JF}$, Rorabeck $\mathrm{CH}$, Bourne $\mathrm{RB}$. Isometric hip abductor strength following total hip replacement and its relationship to functional assessments. Journal of Orthopaedic and Sports Physical Therapy. 1993;18:526-531

11. Vasuda K, Ohkoshi Y, Tanabe Y, Kaneda K. Quantitative evaluation of knee instability and muscle strength after anterior cruciate ligament reconstruction using patellar and quadriceps tendon. American Journal of Sports Medicine. 1992;20:471475 
12. Sepic SB, Murray MP, Mollinger LA, Spurr GB, Gardner GM. Strength and ramge of motion in the ankle in two age groups of men and women. American Journal of Sports Medicine. 1986;65:75-84 
INTERNAL AND EXTERNAL ROTATION STRENGTH VALUES OF FEMALE SWIMMERS AND

WATER POLO PLAYERS 


\section{Chapter I}

Introduction

Swimmers use their shoulders in an overhead position up to 11,000 times per week of training (Magnusson, Constantini, McHugh, \& Gleim, 1995). Thus, shoulder injuries have been cited as one of the major reasons for time loss in competitive swimmers (Magnusson et al., 1995). Elite level swimmers and water polo players use swimming as the main concentration of practice in addition to specific event/sport training. These athletes may not be able to practice if they are sidelined with an injury, and rehabilitating an athlete back to practice entails strengthening the shoulder musculature. The repetitive nature of swimming can frequently lead to soft tissue microtrauma (Magnusson et al., 1995). The difficulty in rehabilitating swimmers and water polo players is that there are no standard strength values available to set goals and determine baselines for these athletes. Thus, return of these athletes to participation has been historically subjective.

Numerous studies have focused on the isokinetic analysis of the rotator cuff and how these muscles function in shoulder movement (Bak \& Magnusson, 1997; Brown, Niehues, Harrah, Yavorsky, \& Hirshman, 1988; Chandler, Kibler, Stracener, Ziegler, \& Pace, 1992; Hageman, Mason, Rydlund, \& Humpal, 1989; Hartsell \& Forwell, 1997; Hinton, 1988; Jenp, Malanga, Growney, \& An, 1996; Kramer \& Hg, 1996; Magnusson et al., 1995; McMaster, Long, \& Caiozzo, 1992; McMaster, Long, \& Caiozzo, 1991; Perrin, Robertson \& Ray, 1987; Tis \& Maxwell, 1996). The strength, and endurance of the rotator cuff are the emphasis of these studies. Many different athletic populations, such 
as swimmers, water polo players, tennis players, and baseball players have been examined (Hinton, 1988; Mont, Cohen, Campbell, Gravare, \& Mathur, 1994). There are multiple studies that examine swimmers and water polo players (Bak \& Magnusson, 1997; Magnusson et al., 1995; McMaster et al., 1992; McMaster et al., 1991); however, there is limited research available that compares the differences of internal and external rotation strength values of swimmers and water polo players. Magnusson et al. (1995) states that guidelines of absolute strength values of internal and external rotation should be set for rehabilitation purposes for both swimmers and water polo players..

Standard internal and external rotation strength values can be used as baselines and goals for injury rehabilitation programs for swimmers and water polo players during rehabilitation of an injury. The strength of the uninvolved upper extremity can serve as a rehabilitation goal of the injured athlete, and is extremely important when pre-injury data is not available to the clinician treating the athlete (Magnusson et al., 1995). The uninvolved extremity can be used as return to sport goals for rehabilitation; however, the influence of handedness and neuromuscular demands of bilateral muscle group relationships of the involved sport raises question as to the efficacy of this prescription process (Perrin et al., 1987). For these reasons, pre-injury data needs to be available for all sports.

Water polo is the most physical of the water sports combining the components of swimming and overhead throwing athlete (Dominguez, 1986). Orthopedic injuries associated with this sport are a combination of the stress of swimming and the overuse syndromes inherent to that sport and injuries common to the throwing motion 
(Dominguez, 1986). This combination of shoulder actions makes treatment of shoulder injuries much more difficult in the water polo player (Dominguez, 1986). Swimming does not contain the throwing action or the level of physicality that water polo possess, however, due to similarities of these two sports, athletic injuries and rehabilitation of the shoulder are treated the same. The inherent differences between the two sports warrants different rehabilitation protocols for injured shoulders; therefore, rehabilitation protocols should be designed specifically for each sport. Currently, no literature exists that examines the differences in shoulder strength between swimmers and water polo players so it is difficult for the athletic trainer to set appropriate rehabilitation protocols.

\section{Purpose of this Project}

The purpose of this study is to examine the internal and external rotation strength of elite female swimmers and female water polo players and to assess differences in the internal and external rotation peak torque and total work values of these sports.

\section{Significance of the Study}

No studies have been done that compare strength values of internal and external rotation for female swimmers and female water polo players. This data may be used to determine strength baselines and rehabilitation goals when setting injury rehabilitation programs for female swimmers and water polo players.

\section{Delimitations}

The study was delimited by the number of subjects, the age of the subjects, the level of competition of the subjects, the exclusion of injured shoulders, the sports involved, the speeds of measurement, the angles of measurement, and the tool of 
measurement (Biodex, System 2). The Biodex, System 2 is the only isokinetic tool available to the test practitioner and is only able to test at certain speeds and degrees of shoulder abduction. Also, the position and testing speeds of the Biodex, System 2 are not truly sport specific to the sports being examined.

\section{Limitations}

The main limitation of the study is that the subjects being tested may not perform to their true potential due to repetitions during the study, practice, or previous muscle soreness.

\section{Assumptions}

This study assumes that all of the athletes of the same sport endure similar training schedules. In addition, it is assumed that the Biodex, System 2 will accurately calibrate and record the data.

\section{Statement of Hypothesis}

The null hypothesis of this study is that there is no significant difference of internal rotation and external rotation peak torque and total work values between female swimmers and water polo players.

\section{Definition of Terms}

Glenohumeral Joint - $\quad$ A multiaxial, ball-and-socket, synovial joint that relies on muscles for support, stability, and integrity rather than bones or ligaments (Magee, 1997).

Overhead Athlete - $\quad$ Sport actions that take place at over 90 degrees of shoulder abduction. 
Isokinetic Testing Device - A device that can test at varying or accommodating resistance while remaining at a constant speed.

Force CoupleTwo groups of muscles that have opposing actions contracting synchronously to enable a specific motion to occur.

Eccentric Contraction - Muscle contraction that occurs while the muscle is lengthening.

Concentric Contraction - Muscle contraction that occurs while the muscle is shortening.

Power Equal to force over time.

Scapular Plane Thirty degrees of lateral adduction of the glenohumeral joint (Magee, 1997). 


\section{Chapter II}

\section{Review of the Literature}

The purpose of this section is to review the literature pertaining to this study. The review will be divided into the following sections: 1) shoulder complex anatomy, 2) examination of overhead athletes, and 3) examination of swimmers and water polo players.

\section{Shoulder Complex Anatomy}

There are numerous anatomical structures that make up the shoulder complex. The glenohumeral, acromioclavicular, sternoclavicular, and scapulothoracic joints comprise the shoulder complex and work in conjunction to allow shoulder movement (see Figure A and B).

Figure A.

$\underline{\text { Shoulder complex anatomy - anterior }}$

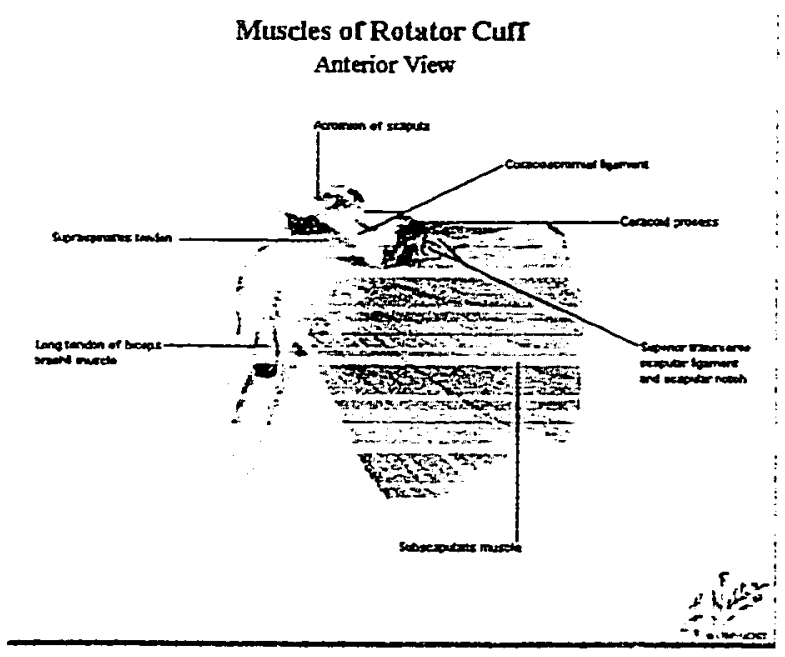


Figure B.

Shoulder complex anatomv - posterior

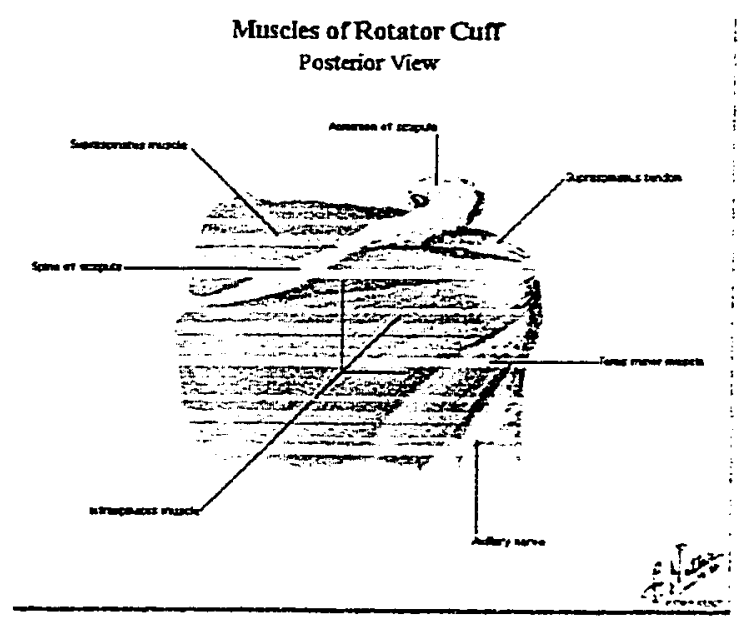

The anatomical structures contribute to the stability of the glenohumeral joint, including the passive restraints (osseous, labrum, ligamentous) and the active restraints [neuromuscular system) (Wilk, Arrigo, \& Andrews, 1997). It is the interaction of these structures which provide functional glenohumeral joint stability (Wilk et al., 1997).

The glenohumeral joint is inherently unstable and exhibits the greatest amount of motion of any joint in the human body (Wilk et al., 1997). Stabilization of the humeral head within the glenoid fossa is extremely important because of the laxity of the joint. Stabilization is accomplished through the combined efforts of the ligamentous structures and surrounding shoulder musculature (Wilk et al., 1997).

The primary active stabilizers of the glenohumeral joint include the rotator cuff muscles (supraspinatus, infraspinatus, subscapularis, and teres minor), the deltoid, and the long head of the biceps brachii (Wilk et al., 1997; Tsai et al., 1991). Wilk et al. 
(1997) also states that the primary role of these muscles is the production of a combined muscular contraction. A force couple between the rotator cuff and the deltoid stabilizes the humeral head within the glenoid fossa during overhead motions (Wilk et al., 1997, Hart \& Carmichael, 1985; Magnusson et al., 1995). The function of the rotator cuff is to dynamically rotate the humerus, depress the humeral head to clear the acromion and to both actively and passively provide glenohumeral joint stability (Chandler et al., 1992; Hinton, 1988; Jenp et al., 1996). The deltoid is the prime mover of shoulder abduction, but cannot work effectively in the absence of the rotator cuff muscles (Schenkman \& Rugo De Cartaya, 1987). The rotator cuff prevents superior movement of the humeral head into the subacromial arch permitting the humeral head to clear the acromion and allow for abduction of the arm (Schenkman \& Rugo De Cartaya, 1987).

The glenohumeral joint is a multi-axial joint that allows for a range of motion in all directions. The shoulder complex functions as a kinetic chain composed of three distinct segments. Movement in any one segment may produce movement in other segments (Schenkman \& Rugo De Cartaya, 1987); for example, movement of the humerus through action of the latissimus dorsi or pectoralis major will produce movement of the scapula and clavicle. The supporting structures, passive and active restraints, of the glenohumeral joint are very important in maintaining shoulder stability, due to these accessory movements.

The scapulothoracic musculature also plays a significant role in shoulder biomechanics by maintaining an optimum position as well as a stable base of support from which the glenohumeral muscles fixate and function (Wilk et al., 1997 and Tsai et 
al., 1991). The three primary roles of the scapula are to increase the positions available for the hand in space by varying the original position of the proximal humerus, to provide stability of the upper extremity during functional activities and to provide attachments for the four muscles of the rotator cuff (Hart \& Carmichael, 1985). Tsai et al. (1991) states that since virtually all arm movement is antigravity, direct muscle control is of great importance for shoulder function.

Use of the shoulder in overhead activity synchronized active contraction of the rotator cuff to depress the humeral head and allow for internal and external rotation without impingement of the rotator cuff tendon under the subacromial arch. Lack of rotator cuff strength will allow the humeral head to decrease the subacromial space and increase the potential for a rotator cuff injury. Thus, it is evident in swimmers and water polo players who have repetitive overhead activity, that the rotator cuff strength and endurance is imperative. However, the standard strength and endurance values for internal and external rotation of the shoulder are not yet known.

\section{Examination of Overhead Athletes}

Athletes involved in sports which require repetitive overhead motion, such as swimmers and throwers, place increased stresses on the rotator cuff as compared to athletes who do not require this movement, since the rotator cuff is constantly contracting to limit the amount of humeral head elevation under the subacromial arch. The glenohumeral joint is in a loose packed, or unstable position, above 90 degrees of shoulder abduction (Hart \& Carmichael, 1985). Because the glenohumeral joint is 
unstable in this position, the rotator cuff must continue to stabilize the humeral head within the glenoid fossa.

Muscle strains, tendonitis, and secondary shoulder impingement are three of the most common shoulder overuse injuries (Copeland, 1993). Athletes who use their muscles in a non-synchronous manner are predisposed to overuse injuries (Bradley \& Tibone, 1991). Rotator cuff injuries may occur due to an inequality of strength of the internal and external rotators causing abnormal firing patterns which lead to these injuries (Copeland, 1993; Magnusson et al., 1995; Chandler et al., 1992).

Hinton (1988) examined amateur baseball pitchers and found significant internal and external rotation strength imbalances between the throwing and non-throwing arms. Hinton also found that peak torque (see Table 4) and total work (see Table 5) for the throwing side internal rotators were significantly higher than the non-throwing side in all tests. 
Table 4.

Mean Rotational Peak Torque Value (ft./lbs.) and Standard Deviations for Internal and External Rotation

\begin{tabular}{|c|c|c|c|c|}
\hline & \multicolumn{2}{|c|}{$\begin{array}{l}\text { Dominant (pitching) } \\
\text { Shoulder }\end{array}$} & \multicolumn{2}{|c|}{$\begin{array}{l}\text { Nondominant } \\
\text { Shoulder }\end{array}$} \\
\hline & $\begin{array}{l}\text { Neutral } \\
\text { TP }\end{array}$ & $\begin{array}{c}90^{\circ} \\
\mathrm{AbTP}\end{array}$ & $\begin{array}{l}\text { Neutral } \\
\text { TP }\end{array}$ & $\begin{array}{c}90^{\circ} \\
\mathrm{AbTP}\end{array}$ \\
\hline \multicolumn{5}{|l|}{$90 \mathrm{deg} / \mathrm{sec}$} \\
\hline Internal & $30.7 \pm 5.2$ & $29.1 \pm 5.5$ & $26.1 \pm 5.1$ & $25.7 \pm 6.4$ \\
\hline External & $18.5 \pm 3.1$ & $19.8 \pm 4.2$ & $17.0 \pm 3.2$ & $19.3 \pm 4.5$ \\
\hline \multicolumn{5}{|l|}{$240 \mathrm{deg} / \mathrm{sec}$} \\
\hline Internal & $22.5 \pm 6.2$ & $20.4 \pm 5.9$ & $19.2 \pm 4.9$ & $18.5 \pm 5.3$ \\
\hline External & $12.2 \pm 3.1$ & $14.5 \pm 4.0$ & $11.7 \pm 2.6$ & $14.5 \pm 3.7$ \\
\hline
\end{tabular}

Table 5 .

Mean Rotational Total Work Values (ft./lbs.) for Internal and External Rotation

\begin{tabular}{lcccc}
\hline & \multicolumn{2}{c}{ Dominant (pitching) } & \multicolumn{2}{c}{ Nondominant } \\
& \multicolumn{2}{c}{ Shoulder } & \multicolumn{2}{c}{ Shoulder } \\
& Neutral & $90^{\circ}$ & Neutral & $90^{\circ}$ \\
& TP & AbTP & TP & AbTR \\
\hline Internal & $109.6 \pm$ & $92.7 \pm$ & $93.9 \pm$ & $87.5 \pm$ \\
& 33.5 & 29.7 & 29.9 & 31.2 \\
External & $51.4 \pm$ & $60.7 \pm$ & $48.3 \pm$ & $62.0 \pm$ \\
& 17.1 & 18.4 & 19.3 & 20.4 \\
\hline
\end{tabular}

Note. From Hinton, 1988

Professional baseball players were not found to follow the same trend. Baseball players have equal rotation ratios at all speeds tests (Brown et al., 1988). These two conflicting studies demonstrate that high-level athletes may counteract muscle imbalances by specifically targeting the external rotators during training. Elite swimmers 
and water polo players may also counteract these muscle imbalances, but no literature is available to confirm these findings.

Chandler et al. (1992) tested collegiate tennis players and found the subjects produced significantly more torque in internal rotation in the dominant arm compared to the non-dominant arm, but there were no side-to-side differences seen in external rotation. Due to the increased internal rotation strength without subsequent external strength, these authors state that muscle imbalances may occur which could increase the likeliness of overload injuries since the external rotators can not adequately decelerate the arm.

Baseball and tennis players show many of the same internal and external rotation characteristics that swimmers and water polo players exhibit; however, the same conclusions cannot be made with swimmers and water polo players because of the differences that exist between the sports, particularly the added overhead throwing activity of water polo players. Because of the increased repetition in water sports compared to baseball and tennis, stresses placed on the shoulder between these overhead sports are quite different.

\section{Examination of Swimmers and Water Polo Players}

Swimmers and water polo players incur many of the same injuries as other overhead athletes, such as baseball and tennis. Swimming and water polo players inherently repeat overhead action with each stroke during practice. This intense training level leads to overuse injuries of the shoulder. Overuse types of shoulder injuries, such 
as muscle strains, tendonitis, and impingement are very common to both swimmers and water polo players (Dominguez, 1986).

The two main orthopedic problems in the throwing athlete appear to be a combination of impingement and instability. Due to the combination of swimming and throwing in water polo players, the treatment of shoulder pain may be much more difficult (Dominguez, 1986). Stresses during the throwing phase of water polo can cause repeated microtrauma leading to labral changes and stretching of the glenohumeral ligaments (Copeland, 1993). The summation of swimming, throwing, and physicality of the game make water polo one of the most demanding sports played today (Dominguez, 1986).

Magnusson et al. (1995) studied masters level swimmers to determine internal and external rotation strength ratios in both arms. The study revealed that the men were significantly stronger than the women in both internal and external rotation; however, there were no statistical side-to-side strength differences in both the males and females. This data is important because it demonstrates a lack of arm dominance in water sports as opposed to other sports. Thus, internal and external rotation strength can be extrapolated to the opposite side.

McMaster et al. (1991) studied elite level water polo players. The water polo players were tested against a control group and were found to be significantly stronger than the controls (see Table 6). Muscle imbalance in the rotator cuff was reported in the water polo players and is significant because muscle imbalance predispose athletes to 
injuries. The differences were more significant at slower isokinetic speeds, with no sideto-side differences being noted.

Table 6.

Mean Values (\%) and Standard Deviations of Adduction and abduction in External and Internal Rotation Ratios in the control and polo groups

\begin{tabular}{lcl}
\hline \multicolumn{1}{c}{ Motion } & Control $(\mathrm{N}=10)$ & Polo $(\mathrm{N}=15)$ \\
\hline Adduction:Abduction & & \\
$30 \mathrm{deg} / \mathrm{sec}$ & & \\
Right & $1.53 \pm 0.12$ & $1.79 \pm 0.34$ \\
Left & $1.44 \pm 0.19$ & $1.87 \pm 0.32$ \\
$180 \mathrm{deg} / \mathrm{sec}$ & & \\
Right & $1.70 \pm 0.25$ & $2.07 \pm 0.66$ \\
Left & $1.58 \pm 0.25$ & $2.00 \pm 0.50$ \\
External:Internal & & \\
30 deg/sec & & \\
Right & $0.74 \pm 0.11$ & $0.61 \pm 0.13$ \\
Left & $0.78 \pm 0.11$ & $0.61 \pm 0.08$ \\
180 deg/sec & & \\
Right & $0.65 \pm 0.14$ & $0.55 \pm 0.15$ \\
Left & $0.66 \pm 0.13$ & $0.56 \pm 0.09$ \\
\hline
\end{tabular}

Note. From McMaster, 1991

The limited amount of research into internal and external rotation strength levels in water polo players and swimmers leaves many unanswered needs for the rehabilitation and prevention of injuries in these athletes. Studies have suggested a difference between the internal and external rotation of water sports and other overhead sports, and differences between male and female swimmers; however no studies have examined male and female swimmers and water polo players to determine internal and external rotation strength differences in these two sports. This study aims to identify strength values of 
internal and external rotation in the shoulder in females, and ascertain if a difference exists in the rotation strengths of swimmers and water polo players. 


\section{Chapter III}

\section{Methods}

The purpose of this study is to see if a difference exists in internal and external rotation peak torque and total work values between female swimmers and water polo players. This section is divided into the following sections: subjects and sampling, testing apparatus, testing phase, and statistical analysis.

\section{Subjects and Sampling}

Ten female collegiate varsity swimmers and fifteen female collegiate varsity water polo players $(n=25)$ from a Division 1A university will be chosen to serve as subjects. All subjects will sign a consent form (see Appendix A) prior to testing. Each subject will have their dominant shoulder tested. Hand dominance will be determined in water polo players by identifying the arm with which they throw and in swimmers by identifying the hand with which they write. Subjects will be excluded if they suffer from an existing shoulder injury or have had a significant shoulder injury requiring extensive rehabilitation or surgery in the past year (12 months).

\section{Testing Apparatus}

Each subject will have their shoulder tested for strength and power in internal rotation and external rotation on the Biodex, System 2 (Medical Systems Inc., Shirley, New York) isokinetic testing device. The Biodex will be calibrated regularly during testing according to the set standards in the Biodex, System 2 handbook. The subjects will be tested for strength at 60 degrees per second, endurance at 240 degrees per second, 
and a sport specific speed of 450 degrees per second. The subjects will be tested in the scapular plane and at 45 and 90 degrees of shoulder abduction (see Figures $C$ and D).

Figures $C$. and D.

45 and 90 degrees of shoulder abduction in the scapular plane
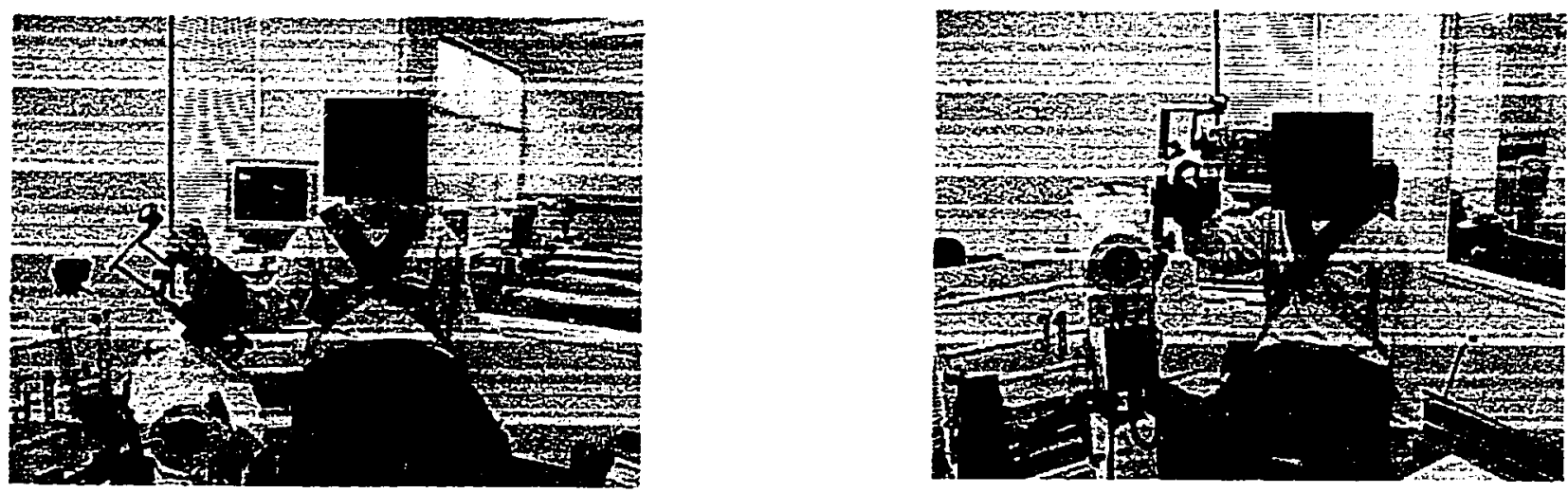

\section{Testing}

\section{Warm-up Phase}

All subjects will be tested in loose-fitting clothes (athletic shorts and T-shirts) to eliminate shoulder restrictions during testing. The testing sequence will begin with a five-minute warm-up either on the Upper Body Ergometer (UBE) at 60 revolutions per minute or testing will take place immediately following a work out. The subjects will be positioned into the Biodex after this initial warm-up is completed. 


\section{Testing Phase}

Each subject will be tested in the seated position and secured to the Biodex chair. The subjects will be secured to the chair with straps across the waist and across the tested shoulder to eliminate accessory trunk movement. The tested arm will be fitted into the dynamometer arm on the Biodex according to the Biodex testing protocol with the shoulder internal and external rotation attachment. The elbow will be stabilized with velcro straps and flexed to 90 degrees (see Figure E).

Figure $\mathrm{E}$.

Stabilization of the Elbow with velcro straps

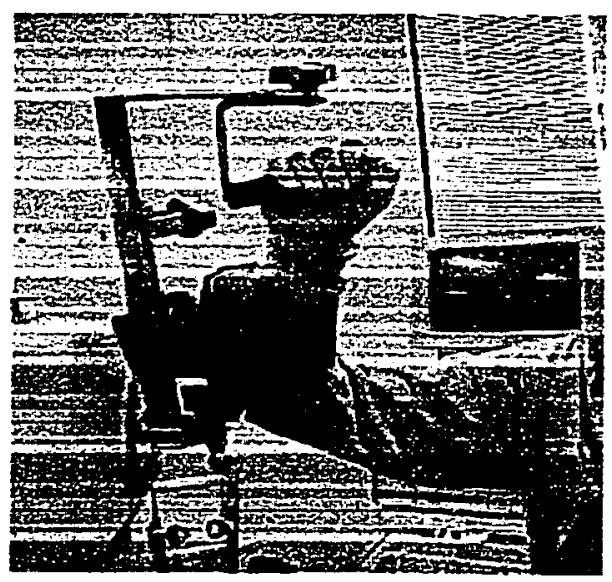

The uninvolved arm will remain in the neutral position at the subject's side during testing

Verbal instructions explaining the testing procedure will be given. Each subject will be given a countdown from 3 before the start of each test. Verbal cues will be given to the subject to encourage maximum effort. Each subject will perform concentric 
contractions of internal rotation and external rotation at each test speed and degree of shoulder abduction. Internal rotation is measured from the arm in the plane of the scapula until it approximates with the trunk and external rotation is measured from the arm in the plane of the scapula until it reaches its anatomical limit (see Figure F).

Figure $\mathrm{F}$.

External Rotation in the Scapular Plane

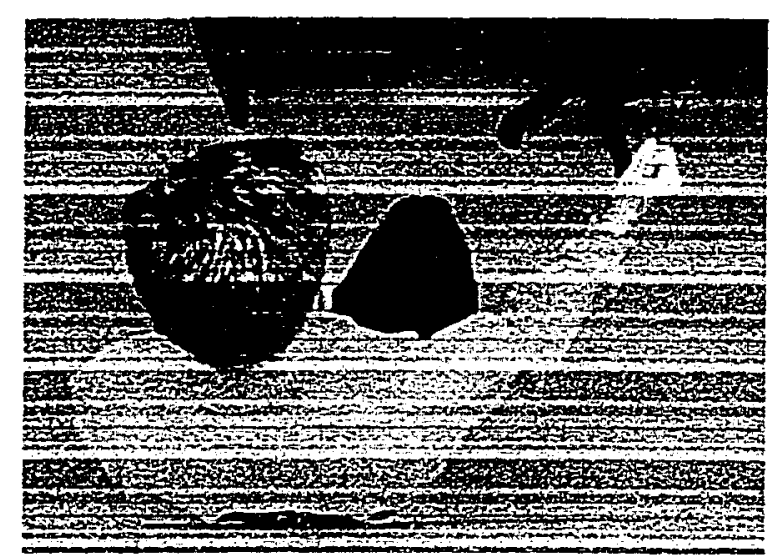

The subjects will perform 5 repetitions at 60 degrees per second and 15 repetitions at 240 degrees per second. Both of these sets will be tested in 45 and 90 degrees of shoulder abduction with a one-minute rest period between tests.

\section{$\underline{\text { Statistical Analysis }}$}

All data will be collected and stored in the Biodex, System 2 computer. Confidentiality will be maintained indicating only the subjects' sport. The Biodex computer will be used to print the test record and each data sheet will be solely identified as swimmer or water polo player. 
Descriptive statistics will be used to determine the mean and standard deviation of the peak torque and total work values produced by each muscle group (internal/external rotators) at each speed and degree of shoulder abduction. Four independent $t$-tests will be calculated on the internal and external rotation peak torque and total work values between the swimmers and water polo players. An alpha level of less than 0.125 will be considered significant. The height, weight, and age of the subjects will be analyzed using descriptive statistics. Each subject will be tested twice and a reliability coefficient will be calculated.

\section{Article Submission}

The article will be written according to the author's notes and be submitted to the Journal of Athletic Training (see Appendix B). 


\section{References}

Bak, K., \& Magnusson, S.P. (1997). Shoulder strength and range of motion in symptomatic and pain-free elite swimmers. The American Journal of Sports Medicine, $\underline{25}(4), 454-459$.

Brown, L.P., Niehues, S.L., Harrah, A., Yavorsky, P., \& Hirshman, H.P. (1988). Upper extremity range of motion and isokinetic strength of the internal and external rotators in major league baseball players. The American Journal of Sports Medicine, $\underline{16}(6), 577-585$

Chandler, J.T., Kibler, W.B., Stracener, E.C., Ziegler, A.K., \& Pace, B. (1992). Shoulder strength, power, and endurance in college tennis players. The American Journal of Sports Medicine, $20(4), 455-458$.

Ciullo, J.V. (1986). Swimmer's shoulder. Clinics in Sports Medicine, 5(1), 115 137.

Copeland, S. (1993). Throwing injuries of the shoulder. British Journal of Sports Medicine, 27(4), 221-227.

Dominguez, R.H. (1986). Water polo injuries. Clinics in Sports Medicine, 5(1), 169-183.

Hageman, P.A., Mason, D.K., Rydlund, K.W., \& Humpal, S.A. (1989). Effects of position and speed on eccentric and concentric isokinetic testing of the shoulder rotators. Journal of Orthopaedic and Sports and Physical Therapy, 11(2), 64-69. 
Hart, D.L., \& Carmichael, S.W. (1985). Biomechanics of the shoulder. Journal of Orthopaedic and Sports and Physical Therapy, 6(4), 229-234.

Hartsell, H.D., \& Forwell, L. (1997). Postoperative eccentric and concentric isokinetic strength for the shoulder rotators in the scapular and neutral planes. Journal of Orthopaedic and Sports and Physical Therapy, 25(1), 19-24.

Hinton, R.Y. (1988). Isokinetic evaluation of shoulder rotator strength in high school baseball pitchers. The American Journal of Sports Medicine, 16(3), 274-279.

Jenp, Y., Malanga, G.A., Growney, E.S., \& An, K. (1996). Activation of the rotator cuff in generating isometric shoulder rotation torque. The American Journal of Sports Medicine, 24(4), 477-484.

Kimura, I.F., Gulick, D.T., Alexander, D.M., \& Takao, S.H. (1996). Reliability of peak torque values for concentric and eccentric shoulder internal and external rotation on the biodex, kinetic communicator, and Lido dynamometers. Isokinetics and Exercise Science, 6(2), 95-99.

Kramer, J.F., \& Ng, L.R. (1995). Concurrent validity of isokinetic dynamometer and hand-held dynamometer protocols in assessment of isometric shoulder rotation strength. Isokinetics and Exercise Science, 5(1), 37-42.

Kramer, J.F., \& Ng, L.R. (1996). Static and dynamic strength of the shoulder rotators in healthy, 45- to 75- year-old men and women. Journal of Orthopaedic and Sports and Physical Therapy, 24(1), 11-17.

Magee, D.J. (1997). Orthopedic physical assessment (Third Edition). Philadelphia, PA: W.B. Saunders Company. 
Magnusson, S.P., Constantini, N.W., McHugh, M.P., \& Gleim, G.W. (1995). Strength profiles and performance in masters' level swimmers. The American Journal of Sports Medicine, 23(5), 626-631.

McMaster, W.C., Long, S.C., \& Caiozzo, V.J. (1991). Isokinetic torque imbalances in the rotator cuff of the elite water polo player. The American Journal of Sports Medicine, $19(1), 72-75$.

McMaster, W.C., Long, S.C., \& Caiozzo, V.J. (1992). Shoulder torque changes in the swimming athlete. The American Journal of Sports Medicine, 20(3), 323-327.

Mont M. A., Cohen, D. B., Campbell, K. R., Gravare, K., Mathur, S. K. (1994). Isokinetic concentric versus eccentric training of shoulder rotators with functional evaluation of performance enhancement in elite tennis players. American Journal of Sports Medicine, 22(4), 513-517

Perrin, D.H., Robertson, R.J., \& Ray, R.L. (1987). Bilateral isokinetic peak torque, torque acceleration energy, power, and work relationships in athletes and nonathletes. Journal of Orthopaedic and Sports and Physical Therapy, 9(5), 184-188.

Rupp, S., Berninger, K., \& Hopf, T. (1995). Shoulder problems in high level swimmers-impingement, anterior instability, muscular imbalance? International Journal of Sports Medicine, 16(8), 557-562.

Schnekman, M., \& Rugo De Cartaya, V.R. (1987). Kinesiology of the shoulder complex. Journal of Orthopaedic and Sports and Physical Therapy, 8(9), 438-450.

Tis, L.L., \& Maxwell, T. (1996). The effect of positioning on shoulder isokinetic measures in females. Medicine and Science in Sports and Exercise, 28(9), 1188-1192. 
Tsai, L., Wredmark, T., Johansson, C., Gibo, K., Engstrom, B., \& Tornqvist, H. (1991). Shoulder function in patients with unoperated anterior shoulder instability. The American Journal of Sports Medicine, 19(5), 469-473.

Walmsey, R.P., \& Dias, J.M. (1995). Intermachine reliability of isokinetic concentric measurements of shoulder internal and external peak torque. Isokinetics and Exercise Science, 5(2), 75-80.

Wilk, K.E., Arrigo, C.A., \& Andrews, J.R. (1997). Current concepts: The stabilizing structures of the glenohumeral joint. Journal of Orthopaedic and Sports and Physical Therapy, 26(6), 364-379. 


\section{APPENDIX A \\ Informed-Consent Form \\ Internal and External Rotation Strength Values of Female Swimmers and Water Polo Players}

1. Christopher Ferry, ATC who is a Graduate Assistant at San Jose State University has requested my participation in a research study at this institution. The title of the research is "Internal and External Rotation Strength Values of Collegiate Swimmers and Water Polo Players".

2. My participation in the study will involve an isokinetic test on the Biodex, System 2 of my dominant shoulder. The duration of the test will be approximately 20 minutes.

3. I understand there are foreseeable risks of discomforts to me if I agree to participate in the study. The only risk of participation in this study would be muscle soreness 1-2 days following testing.

4. I understand that the results of this research may be published but that my name or identity will not be revealed. In order to maintain confidentiality of my records, Christopher Ferry, ATC will only use the codes of male and female and swimmer and water polo player. The tester, Christopher Ferry, ATC, will be the only person who knows the names of the subjects.

5. I have been informed that I will not be compensated for my participation.

6. I have been informed that any questions I have concerning the research study or my participation in it, before of after my consent, will be answered by Christopher Ferry, ATC, or Serena Stanford, PhD, AVP of Graduate Studies and Research.

7. I understand that in case of injury, if I have questions about my rights as a subject/participant in this research, or if I feel I have been placed at risk, I can contact the Chair of Human Subjects Research Review Committee.

8. I have read the above information. The nature, demands, risks, benefits of the project have been explained to me. I knowingly assume the risks involved, and understand that I may withdraw my consent and discontinue participation at any time without penalty or loss of benefit to myself. In signing this consent form, I am not waiving any legal claims, rights, or remedies. A copy of this consent form will be given to me.

Subject's Signature

Date

9. I certify that I have explained to the above individual the nature and purposes, the potential benefits, and possible risks associated with participation in this research study, have answered any questions that have been raised, and have witnessed that above signature.

10. These elements of informed consent conform to the Assurance given by San Jose State University to the Department of Human Performance to protect the rights of human subjects.

11. I have provided the subject/participant a copy of this signed consent document. 
APPENDLX B

Journal of Athletic Training

Authors Notes 


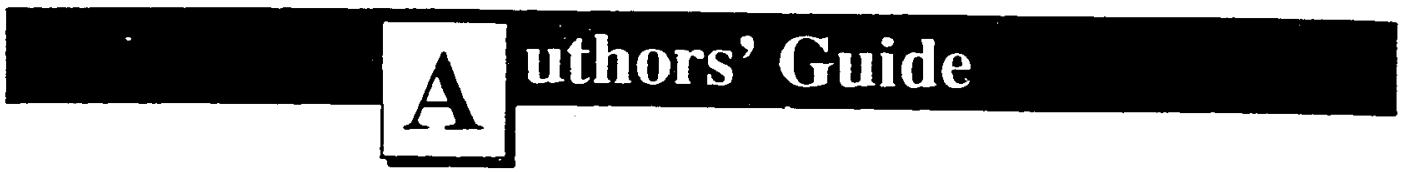

(Revised January 1998)

The mission of the Joumal of Athletic Training is to entrasce communication arnong professionals interesed in un quality of heslin care for the physically active urough education and researth in prevention ef evaluat injures.

\section{SUBMISSION POLICIES}

1. Submis one original and five copies of the entre manusenpt tincludeng uablo and figures) Lo: Joumal of Athlefic Troining Submisions. Hughsion Spons Medicine Foundation. lnc. 6262 Veterans Patway. PO Bax 9517. Columbur. GA 31908 . The iem fipure refers. to nems that are no edrable. either halfiones iphorographs) ox line art (ctaris. graphs, treings. sehematk drawingst of combinations of the rwo. A rable is

reects to be typeset. All manuscrmps must be sccompanied by bitle signed by exch author and must contun the lollowing salements: This manuscrip it contains onginal unpublished materal tha nas been subrritled solely wo the Joumal of Athletic Training. 2) is nox under simulta. neous revew by any oher publication. and 3 ) sion has been made concerning its suitability for publication by the Joumel of Athletic Training. In consideration of the NATA' aking action in reviewing and editing my submussion. I the undersigned aurhor herety consfer. assign or aherwise convey all everu that such work is publisted by the NATA. Further. I verity that I have conteriblined in vem if of the current an our Guide- By signing the current Aluthors Guide- By signing the lerrs. the authors apree to comply whth all statements. Manv kerer will nox be reviemed senpls becone the property of the NATA. Authors apres to scrept any minor cortec hions of the manuscript made by the editors.

3. Each author muss have contributed to the arick. This means that all coauthors shoukd have made some useful contibution to the susdy. should have had a hand in writing and revising it. and should be expected to be wble to detend the study publicly agunst criocism.

d. Finuxial support of provision of supplies used in the study must be actnowledped. Grant or conusa numbers should be included whenever possible. The complets name of the funding institution or sgercy should be given. along with the city and sule in which it is located. If individual author were the recipients of funds their nemes

conmercial or propnetary interess commercial of propnetary interest in any the subject of the anicte in question Authors must also revel if they theve any fortars must also reveal if they have any financia (10) in a drue or device deceribed in (he aricke.

6. Fox experimental invexigations of humen ox animal subjers. state in the "Mechods" section of the monuscript that an approprate insutulional review boand approved the project. For those unvesugators who do not have formal ethus revew comminter (institurional or repronall the ponnciples oudined in the Deciaration of Helsinki should be followed 14 I 4 World Medical Assembly. Deciasation of Helsinki: recommendatoon. guiding physicians in biomedical researth
involving human subjers. Bull Pon Am
Health Orear 1990:24:606-609). For invesugations of human subjects state in the "Methods" section the manner in which intomed consenk was obeained from the subjeces. (Repnnted with permissson of JAHAA
$1997-278: 08$. copyrigh 1997. American 1997:278:68. Copyrig

7. Signed relestes are required to verify pemis sion for the Soumal of Athiefic Trainiss If 10 reproduce materials taken from other sources inciuding text figures or ubles: 2) 10 reproduce phocographs of individuals: and 3) to publish : Case Repon A Case Repor by the individual being discussed in the Case Repor. Release forms ciscussed in the Case the Edilorial Office and from the JAT web

8. preze, or authors may use their own forms. ble blind review prene tro Aune uses a boube identified in any way excep on the bik pape.

9. Manuscenpes are ediled to improve the effectivesess of commenication between wuthor and readers and to aid the author in presenting a work that is compatible with the style poticies found in the AMA Marual of Sntr. proofs are sent to the author lo proofreding when the sticte is typeset for publication. It is imporand that they be renumed withis 48 hours. important changes are permitted. bu wurhors will be cherged for excessive alleraunons. 10. Published manusconps and accompanying
work cannol be renumed Unused manuscrips will be recumed if submined with a stamped self-addressed etrvelope.

STYLE POLICIES

11. Exch page must be printed on one side of $81 /$ by 11 -inch pisin paper. double spaced, with

12 One-unch matgins. Do nol nght justify pages organized in the ordec listed below. with och section beginang on a separate page s. Tille pege

b. Acknowledgrients

c. Abseract and Key Words tfirsi numbered

d. Text) (body of manusenpx)

c. References

f. Tubles (each on a separate page) e. Lepends to figures

h. Figures

13. Begin mumbering une pepes of your mantscrip with the abstrea page is 1 : then.

14. consecutively number all successive pages. Units of mensurement shall be recorded as 51 units. as specified in the AMA Mornal of Snte. excepp for engular displacement, which should be measured in degrees rather than radians. Examples include mass in kiloparams (kgl heighs in centimeters $(\mathrm{cm})$. velocity in meters per second imsece or m/recl. ungu-

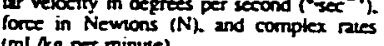

15. Tilles should be brief within deseriptive limis (a 16-word maximum is recommended). If disability is the rejevans factor in an arisle. in ine oitle if a solhnique is the maluded reason for ine report. it should be in the ville. Often boit should apper.

16. The titie parge should also include the name. litte. and afrliation of each arthor and the nume add and $E$-mait coctress of the aurtor wo whom correspondence is to be directed.
17. A servetured abstract of 75 lo $20 x 1$ wards mus cccompany all manusconpls. Type the com. piese title ibut not the wuthoss names) al the 10p. skip two lines. and begin the atsurser. liems that we needed differ by type of arickLiterature Review: Objective. Dats Sources. Data Synthesis. Conclusions Recommendations and $\mathrm{Ker}$ Word: Oriznal Research micles: Objective. Dexugn im! Setung- Subjects. Mesuremesu. Kesuls. Conctussions. and Key Words: Cuse Kro ports: Objective Back ground. Diflerenutal Diapmosis. Treament, Uniqueneak Conclusions und Key Worts: Cinical Techniques: Objective Beckeround Description. Clinxal Advanenges and Key Words. For the key Words critry. use three to five words that do no sppear in the tirle.

Begin the wexi of the manuscropt with an incrocuctory parapraph or noc in which the purpose or hypothesis of the aricke is clearly ched and

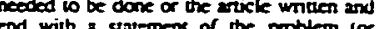
and with a dase or the ar the problem ior controversyl. Highlights of the mose promiwubject are often approprive for the introdu. tion but a decilied revew of the litepiture should be reserved for the discussion saring In a one- to two-pare discussion satimn. literature. idenufy and devetop the magniturs: and significance of the controversy poinune out differenees among obers" resulis, conclus. sions. end/or opinions. The introduction is nor the place for grear detril: stale the facts in onef specific statemenos and reference them. The detail betongs in the discussion. Also. ar overview of the manuscrip is pan of une absenes not the introduction. The setive voice is preferred for examples, consult the A MA M Marual of Snite.

9. The body or main pant of the manuscrip vanes cocording to the type of aricke (examples follows: however the body should include a discussion werion in which the importance of the matcrial presented is discussed and reisted lo other perinent literaure. Liberal use or heading. and subther inge chars.

The bxdy of an Oriqinal Research snn.k consusus of a methods section. a preventiresuls the methods aceion should con thin sufficent detsil conceming the meth ads, procedures and epparaing the meth ods, procecures and epparzius employed The results should be summanized usune desernpive and inferemial sarissios and a few well-planned and carefully conserveled illustritions

b. The body of a Lheranure Review arick should be organized into subsections in which retated thoughts of odvers are presented summanized and referenced Exh sutsection should have a heading and bref summery. possibly one sentence. Sections musi be arranged so that they progrexsivety focus on the problem or question poned in the ineroduction.

c. The body of a Cese Report should incitude the following comporems: persmat dus lape sex, mee. masital sarus. and cecups: tion when rekevant-but not name). chicf complaint hissory of prexerts complains (including sympromsL resulls of physieal

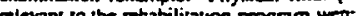
relevant to the refubiliaxon program were ... Tuls exal his and clinieal course irtatilitarn unil on 


\section{A uthors' Guide}

Ifer rexum to compecitiont enteria for retum to competion ind deviation from expectarions twhat makes this case unverel.

d. The body of a Clinical Tecbnique arricle should inelude both the how und why of the technique: a step-by-step explanation of how to periorm the reehmique. supplemented by phocopraphs or illustrations. and an explanation of why the technique should be used. The discussion concerming the whr of the technique should review similat techniques. point out how the new technique differs. and explain the advanuges and disadvanuages of the technique in comparison

20. Consmunicutions articles inciuding officis Posioion Statements and Policy Statements from the NATA Pronouncements Comm cees vechnical notes on such tophes as resenth desipn and wassos: and arvicies on orter proilessional tssues of interest to the raderwho tors a suggestion for such ? paper is advisect to contact the Editorial Office for instructions.

21. The manuscrip should not have a separate summary secuos-che abserst serves as a sumniry. It is approposice however. to be the arocke logether with a suminar pargroph $\alpha$ list of conctustions at the end of the discussion sectoon

22 References should be numberod consecuovety. using superscrpped arbic numerals.

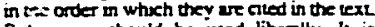
Relerences should be used liberally. It is unetical to present octers ideas as your Own. Also. use references so that readers who desite further informason on the wopic can bencfit from your scholsrship.

27. References to sticles of books, published or mocepted for publicanon. or to papers presemed as professional meeangs are listed in numerical arder at the end of the manuscip. Journl vile abbrenatons conform to Inde Mecticus syle Examples of references are illustrated betow. See the AMA Marnal of Style for ocher exaroples.

1. van Dyke IR IIL. Von Trapp JT Jt. Smich BC Sr. Artroseopic mamagement of possoperave arunchibrosis of the knee pounc Joint Surg Br: 1995:19-517-525.

2 Council on Scientife Affuits Scienotic issoes in dug tesoing. JMMA 1987-257: $3110-3114$.

1. Fuscher DH Jones RT. Growing Old in Amence New York NY: Ouford

2 spencer $\pi$. Brown $\alpha$. Imurunology of influenza In: Kilboume ED. Gray JB. ods

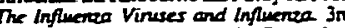
at Otinda FL: Aademic Press Ine 1975:373-393.

1. Sterce IA. Swiss ball rehabilitation exercise. Presented at the 47th Ansual Moct inf and Clinical Symposia of the Nasions Ambetic Triners Associnoon: June 12

24. Table Siyk 1) Titie is boldt body and colum The Syen rites in porchedes: 3) numbers are alipred in

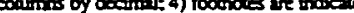

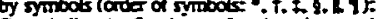

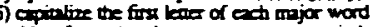

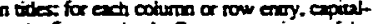
ox the fing word only. Sex a cirmen isue o $\alpha$ the soumd for onemples

25. All black and while line an should be submitted in camen-ready form. Lipe arr sbould be of $800 d$ quality: should be clearly presented on white paper with black ink. ans serif typeface. and ao box. and should be prined on a laser prialer $\rightarrow$ do dot macrix. Figures that reqain readable at their final size (either one column or two columas wide) Phocone cols should be glossy black and white prints. Do not use paper elips. write on phorographs. or araet phorogn ths io sheets of paper. On the revere of each figure attach a write-on label with the figure number. name of the author. and on arrow indicating the top. (Nove: Prepare the label before affixing it to the figure.) Authors should submit one onginal of each figure and five copies for review.

26. Authors must request colot reproduction in a cover letter with the submitted manuserip. Authors will be noxified of the additional cost of color reproduction and gust confirm aeceplance of the eharges

27. Legends to figures are numbered with Aribic purmerals in order of sppearance in the lext Legends should be printed on seperate pages are marusenpe 

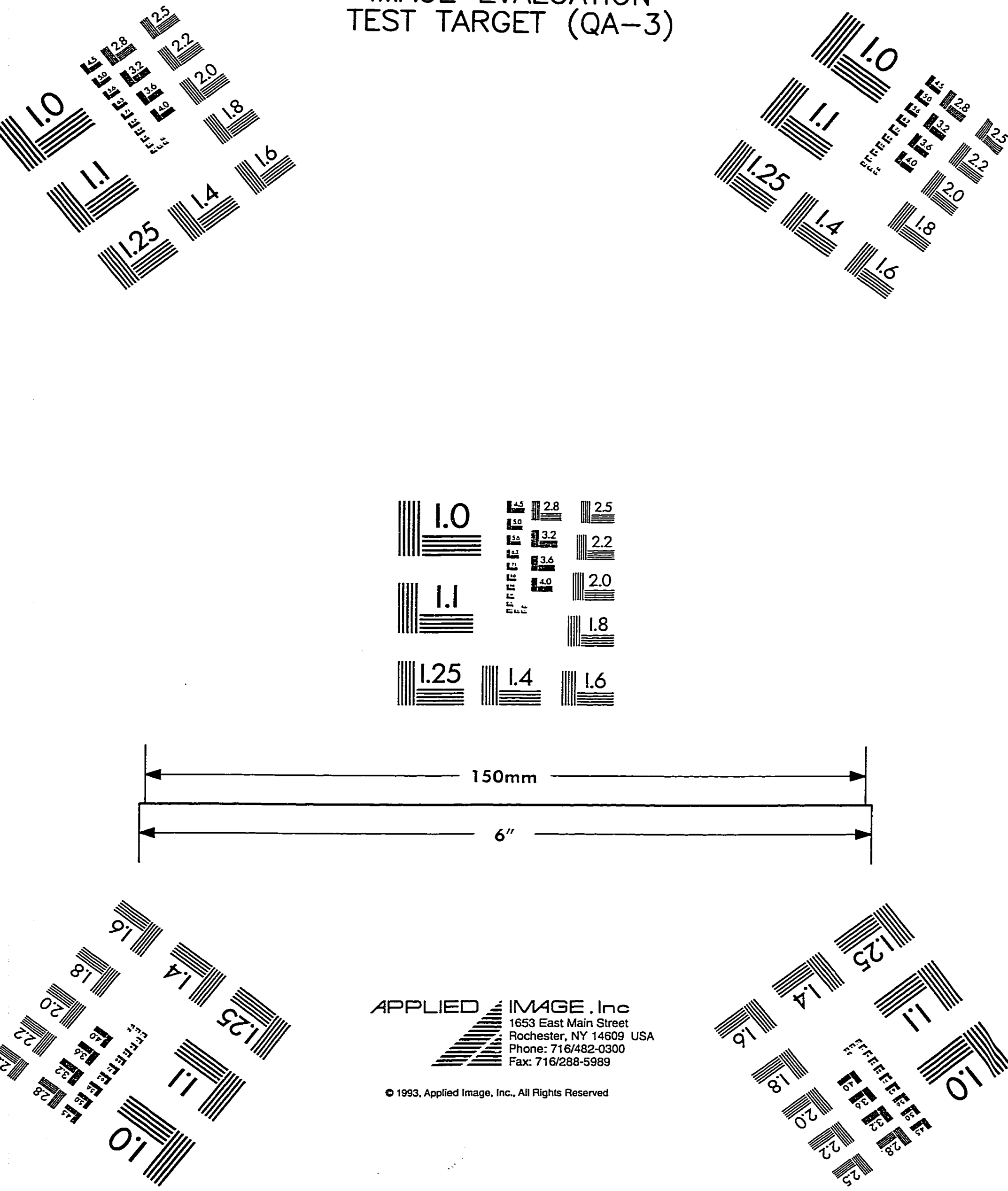